\title{
LOUCURA E COMPLEXIDADE NA CLÍNICA DO COTIDIANOa
}

\author{
Madness and Complexity \\ in the Daily Life Clinic \\ Locura y Complejidad \\ en la Clínica del Cotidiano
}

Raul Fernando Sotelo Prandoni

Maria Itayra Coelho de Souza Padilha

\begin{abstract}
Resumo
Este estudo tem por objetivo investigar a influência da reforma psiquiátrica possibilitando uma nova abordagem antimanicomial aderente à compreensão do sofredor psíquico como sujeito complexo e subjetivo, em si próprio. 0 referencial teórico é Michel Foucault. É uma pesquisa qualitativa que usa entrevista. A análise dos dados está centrada na analítica interpretativa. Surgiram dois enunciados de análise: a) Autonomia: um operador terapêutico; b) Direitos humanos como possibilidade de relação com as diferenças. Observa-se que mudanças de concepções são gradativas, e o ponto de partida somos todos nós, trabalhadores, usuários e familiares. Esta lógica proposta pela Política de Saúde Mental implica: integração de alguns projetos unindo as ações de saúde e saúde mental; criação de espaços férteis na conquista da reabilitação em saúde mental; e qualidade na troca de informações entre os trabalhadores de saúde mental, que são pontos-chave para o avanço e consolidação desse novo modelo.
\end{abstract}

Palavras-chave: Saúde Mental. Psiquiatria. Enfermagem. Autonomia Pessoal. Direitos Humanos.

\begin{abstract}
This paper has the objective to reflect about the Psychiatrist reform for the conduction to the humanization of the madness and the reflection of an anti-mental hospital approach which adheres to a new understanding of the psychic sufferer as a complex subject and self-subjective. This work is supported in the work of Michel Foucault. We make a qualitative research, being the method of production of datum the interview. The analysis of the datum obtained in the interviews is centered in the Interpretative Analytic Method. We have two statements of the analysis. 1) Autonomy: a therapeutic operating 2) Human rights how possibility of relationship of differences. In this way we can see which changes in the conceptions are gradual and the starting point, are all of us, workers, users and relatives. The logic proposed by the Politic of Mental health, the integration of some projects uniting the actions of health and mental health and the creation of fertile fields in the conquest of the recovery in mental health and the quality in the exchange of information among the workers of mental health are key points in the advance and consolidation of this new model.
\end{abstract}

Keywords: Mental Health. Psychiatry. Nursing. Personal Autonomy. Human Rights.

\section{Resumen}

Este estudio tiene como objetivo investigar la influencia de la reforma psiquiátrica haciendo posible un nuevo abordaje antimanicomial adherente a la comprensión del sufridor psíquico como sujeto complejo y subjetivo en sí mismo. El referencial teórico es Michel Foucault. Es una investigación cualitativa, siendo el método de producción de datos la entrevista. El análisis de los datos obtenidos en las entrevistas está centrado en el método Analítico Interpretativo. Surgieron a partir de las regularidades enunciativas dos enunciados de análisis. 1) autonomía: uno operador terapéutico; 2) derechos humanos como una posibilidad de relación con las diferencias. En este sentido, observase que cambios de concepciones son graduales y el punto de partida, somos todos nosotros, trabajadores, usuarios y familiares. Esta lógica propuesta por la Política de Salud Mental; implica en la integración de algunos proyectos uniendo las acciones de salud y salud mental; la creación de espacios fértiles en la conquista de la rehabilitación en salud mental y la calidad en el intercambio de informaciones entre los trabajadores de salud mental que son puntos claves para el avance y consolidación de ese nuevo modelo.

Palabras clave: Salud Mental. Psiquiatria. Enfermería. Autonomía Personal. Derechos Humanos. 


\section{A HISTÓRIA QUE PERMITIU A ESCOLHA DA TEMÁTICA}

A presente investigação está centrada na reflexão de uma abordagem antimanicomial aderente à nova compreensão do sofredor psíquico, como sujeito complexo e subjetivo em si próprio. Consideramos, também, que esta proposta está em consonância com as exigências deste novo tempo e em sinergia com nosso compromisso ético, dentro da utopia e da luta sistemática por "uma sociedade sem exclusão". No entanto, baseados em nossas experiências de trabalho e pesquisa nos serviços de saúde mental, observamos que, apesar das transformações teórico-jurídico-políticas, o fazer do profissional da Saúde Mental adquire uma forma, na qual ainda predominam as relações de poder disciplinar utilizando, assim, seus dispositivos, entre eles: a vigilância hierárquica, a sanção normalizadora e 0 exame $^{1}$. Estes dispositivos empregados no cuidado ao sofredor psíquico,cerceiam sua liberdade e, objetivando0 , inviabilizam sua emancipação, o que pode ser mais um obstáculo na sua ressocialização.

Nosso trabalho para uma adequação do indivíduo sofredor a um convívio social "normal" foi, e ainda é, uma meta no cuidado ao sofredor psíquico. Ainda existe socialmente o mito sobre o significado da expressão "normal", mito que também é incorporado pelo profissional da ciência "psi" fazendo com que exista uma "obsessão" nessa busca de "adequação" do sofredor ao social. Também, neste mesmo sentido, é utilizada, para benefício do social, uma escolarização imposta ao sofredor que indica como, quando e o que se deve fazer. Em contrapartida, em caso de infração a esse "dever ser" acontece 0 ato punitivo. Não podemos esquecer que sempre por trás de uma disciplina funciona um pequeno mecanismo penal, isto é, a sanção normalizadora aparece com freqüência no cuidado manifesto ao sofredor psíquico. Este dispositivo da disciplina estabelece, segundo Foucault:159, (...) infrapenalidades; quadricula um espaço deixado vazio pelas leis; qualifica e reprime um conjunto de comportamentos que escapava aos grandes sistemas de castigo por sua relativa indiferença.

A compreensão da loucura como entidade nosológica, síndrome ou sintomas isolados do sujeito, como tradicionalmente é descrita, ou seja, a alteração, com evolução contínua e progressiva, que altera de maneira persistente a atividade psíquica (Ey:200), inaugura um novo espaço para a loucura e limita 0 deslocamento do sujeito no eixo saúde-doença. Morin ${ }^{3: 51}$ apresenta uma outra compreensão da loucura, não mais como exterior ao sujeito, mas como uma condição humana: (...) a compreensão humana nos chega quando sentimos e concebemos os humanos como sujeitos; ela nos torna abertos aos seus sofrimentos e alegrias.

Neste estudo, a utilização do termo loucura centrase no entendimento de primeiramente mostrá-la como um outro discurso de verdade, de difícil compreensão pela sua linguagem mascarada (de ordenação e vertigem) e que utiliza a desrazão para se mostrar ao outro da relação. Simboliza, ainda, em nosso entendimento, uma verdade única para seu emissor e um significado oculto para o receptor. As palavras (linguagem mascarada) vêm, portanto, dar uma opacidade à transparência da vida. Uma outra possibilidade de olhar essa mesma loucura é também compreendê-la como a vida sendo tomada por acontecimentos que extrapolam as palavras e os códigos disponíveis, ou, mesmo, o repertório textual comum.

Portanto, o louco, ao lançar-se na vida localiza-se estruturalmente em um lugar de fragilidade frente ao mundo. E qual pode ser o sentimento do sofredor psíquico, nesse momento, em que a sua vida se encontra, ao mesmo tempo, entremeada por sentimentos contraditórios entre a grandeza e a miséria? A resposta a esta pergunta é o que cotidianamente vemos no cuidado, um desamparo, uma ausência de abraços para esses sentimentos que "pulam" entre o poético e o prosaico e uma ausência de compreensão, quando o sofredor está à mercê do irrepresentável, do inominável, do invisível e do inaudível.

A partir destas constatações e na tentativa de compreender o sentido e o significado da "loucura" e do "louco", propomos a reflexão sobre uma abordagem antimanicomial de cuidado em saúde mental que visa, tão somente, à concretização de uma relação de cuidado ético-solidária e produtora de autonomia. Nesta busca, pesquisando a literatura que permita uma maior compreensão desta realidade, propomos a adoção daquelas teorias que possam dar suporte teórico ao universo da investigação proposta. Assim, como teórico central deste estudo escolhemos Michel Foucault, por encontrarmos em sua leitura a complexidade sobre a microfísica do poder necessária à análise dos jogos de verdade e os dispositivos disciplinares de poder, ou seja: e se, de uma maneira formal, o regime representativo permite que, direta ou indiretamente, com ou sem revezamento, a vontade de todos forme a instância fundamental da soberania, as disciplinas dão, na base, garantia da submissão das forças e dos corpos (Foucault:195). Este estudo tem por objetivo, investigar a influência da Reforma Psiquiátrica, que possibilita uma nova abordagem antimanicomial aderente à compreensão do sofredor psíquico, como sujeito complexo e subjetivo em si próprio. 
CAMINHOS E TRILHAS: 0 DIMENSIONAMENTO METODOLÓGICO

Este estudo consistiu na busca da compreensão do significado dos discursos das pessoas envolvidas no cuidado em saúde mental. Portanto, fez-se necessário analisar o que elas dizem, fazem e pensam a respeito da vivência (sofrimento) e do cuidado, procurando, então, extrair o significado desta experiência. É um estudo qualitativo cujo campo é o recorte espacial que corresponde à abrangência, em termos empíricos, do recorte teórico correspondente ao objeto da investigação (Minayo: $\left.{ }^{4101}\right)$. Concordando com esta idéia, Trentini e Paim ${ }^{5: 80}$ dizem que, a escolha do espaço físico da pesquisa depende do enfoque da pesquisa e pode consistir em mais de uma área geográfica.

0 total de sujeitos envolvidos na pesquisa foi de 13 pessoas divididas em dois grupos. Um grupo foi denominado grupo dos sofredores psíquicos e familiares (três pessoas), e o outro grupo foi denominado trabalhadores de saúde mental (dez pessoas). Todos os sofredores psíquicos e familiares participam do Movimento Nacional da Luta Antimanicomial e/ou dos serviços de atenção à Saúde Mental. Os profissionais da Saúde Mental participam do Movimento Nacional da Luta Antimanicomial e/ou do cuidado nos serviços alternativos de atenção à Saúde Mental, e/ou da formulação de diretrizes nas políticas de saúde mental.

$\mathrm{Na}$ produção de dados, utilizamos como instrumento a entrevista semi-estruturada ou guiada, uma expressão utilizada por Richardson ${ }^{6: 212}$. Ele diz que: (...) 0 pesquisador conhece previamente os aspectos que deseja pesquisar e, com base neles, formula alguns pontos a tratar na entrevista. A opção pela entrevista como instrumento de pesquisa visou obter aqueles aspectos considerados mais relevantes para o estudo. Por meio da entrevista almejamos obter informações detalhadas que pudessem ser utilizadas em uma análise qualitativa. Os aspectos éticos foram salvaguardados por meio do Termo de Consentimento Livre e Esclarecido elaborado de acordo com a Resolução CNS n. 196/96, que trata de pesquisa que envolve seres humanos (Lisboa ${ }^{7}$ ). Da mesma forma, foram garantidos 0 anonimato dos entrevistados e o sigilo das respostas ${ }^{\mathrm{b}}$. Além disso, o estudo foi aprovado no Comitê de Ética em Pesquisa da Universidade Federal de Santa Catarina, antes de seu início. As entrevistas ocorreram no período de fevereiro a outubro de 2003.

A análise dos dados obtidos nas entrevistas está centrada na Arqueologia do Saber ou Analítica Interpretativa, como é, também, definida como inicialmente um diagnóstico do que consideramos nossa insatisfação comum (Rosário ${ }^{8: 59}$ ). A noção apresentada ressalta que Foucault procede a um ato interpretativo que enfoca e articula, dentre todos os perigos e insatisfações que encontramos em nossa sociedade, aqueles que podem ser compreendidos como paradigmáticos (Rabinow et al.9:279).

Ao término das entrevistas, fizemos uma leitura exaustiva de seus conteúdos, destacando as regularidades próprias dos discursos. Posteriormente, foi realizada uma apresentação específica dos enunciados por temáticas semelhantes, demonstrando que, no interior de uma mesma prática discursiva, existem diferenciações, contradições, opiniões opostas e conexões em seqüências diversas. A partir das regularidades enunciativas, realizamos a derivação de dois enunciados de análise: a) Autonomia: um operador terapêutico; b) Direitos humanos como possibilidade de relação com as diferenças.

\section{AUTONOMIA: UM OPERADOR TERAPÊUTICO}

A pós-modernidade ou contemporaneidade tem nos reservado uma série de mudanças e transformações comportamentais. Fica evidente, em todas as áreas do conhecimento, a falência de um modelo e a conseqüente necessidade de se estabelecer novos modelos ou paradigmas. Não cabe, no momento, estabelecer uma análise pormenorizada de tais mudanças. No entanto, procuramos nos ater à reflexão em torno das transformações que se opera em duas importantes dimensões: o entendimento dos trabalhadores de Saúde Mental sobre os modos de atenção e a percepção do sofredor psíquico e seus familiares sobre esses mesmos modelos.

A noção da loucura não é natural, mas profundamente histórica e cultural. Portanto, cada época irá proferir o discurso que revela seus ideais e expectativas em relação a ela, tendo estes discursos conseqüências constitutivas sobre o sofredor psíquico. Mas que discursos são estes? Que práticas tais discursos engendram? Como definir ou especificar a experiência de ser sofredor psíquico e as vicissitudes deste acontecimento na atualidade? Que sentimento 0 sofredor psíquico desperta nos trabalhadores de Saúde Mental? Como falar de encontros e desencontros entre trabalhadores de Saúde Mental e sofredor psíquico? Responder a estas e outras questões não é tarefa fácil, pois implica uma reflexão profunda de nossos atos, gestos e palavras, como apontam os discursos abaixo:

(...) Nós profissionais de saúde mental precisamos olhar a história e nos perguntarmos: 
O que falta e o que sobra na atenção ao sofredor psíquico? Creio que esta oportunidade que estou tendo de ser entrevistada é muito importante para nós trabalhadores de saúde mental, porque nos faz pensar e repensar a nossa prática, porque nos coloca novamente nas mãos a possibilidade de reescrever a história e marcar os rumos da saúde mental no presente (Sobrancelhas).

(...) Eu não consigo pensar a loucura separada da minha vida, do dia-a-dia. E acho que não consigo mais pensar uma outra forma de atendimento que não seja aquela que a gente está tentando construir. Porque eu sinto que este é um processo de transição, que nós não estamos com nada pronto ainda. É preciso que se reflita e se discuta muito ainda [...] 0 que eu vejo hoje é que nós estamos vivendo todo esse processo de mudança, propondo essa mudança para esse novo olhar, esse novo cuidado para a loucura (Corpo / Alma).

0 grande número de encaminhamentos para a psiquiatria é o reflexo da impossibilidade de uma reflexão, de uma escuta mais refinada e da possibilidade de se pensar outras formas de apreensão e relação com o sofrimento psíquico, ultrapassando a forma vinculada apenas ao isolamento ou mesmo, ao tratamento medicamentoso. Trabalhar a subjetividade do sofredor inclui a possibilidade de se operarem transformações significativas na realidade considerando-se, assim, a história, as singularidades, as identidades do sofredor. Ampliam-se, então, seus horizontes, novas possibilidades de vida são construídas e se caminham para o despertar e fortalecimento da autonomia desse sofredor. No discurso a seguir observa-se que a orientação para 0 trabalho oferecida pelo serviço de saúde mental constitui-se, ainda, em mais uma estratégia de cuidado.

(...) Então, nós tínhamos oficinas de culinária, tínhamos o pessoal que fazia reciclagem de papel. Então, os pacientes começam a ter uma ocupação, a se relacionarem, começam a dispor do tempo e a se sentirem úteis. Porque, na reciclagem de papel, eles fazem todo o processo: juntam o papel, batem, preparam até fazer as placas de papel. A partir daí, eles aprendem a pintar, desenhar, fazer cartões, fazer envelopes e, no final, eles vêm o trabalho pronto, acabado e eles se sentem úteis (Hematomas).

A esse respeito, cabe destacar que Ortega ${ }^{10: 153}$, referindo-se ao cuidado de si foucaultiano, diz que:
O cuidado de si é concebido como o ponto de resistência preferencial e útil contra o poder político, e localiza o objetivo político no fenômeno de novas formas de subjetividade. 0 indivíduo alcança autonomia mediante as práticas de si e mediante a união da própria transformação com as mudanças sociais e políticas.

Afinal, se a cidadania está ligada à produção e ao trabalho, o sofredor psíquico, muitas vezes impossibilitado de exercer um trabalho, não é reconhecido como um cidadão, ou seja, aquele que possui direitos e deveres na sociedade. As oficinas protegidas e serviços de atenção à saúde mental devem estimular a formação de cooperativas de trabalho, nas quais o sofredor possa exercer seu direito ao trabalho. A autonomia está intrinsecamente relacionada com o exercício da cidadania ${ }^{11}$. Embora, na atualidade, o não-trabalho já não corresponda mais ao conceito de perda de cidadania, tendo em vista o grande número de pessoas na categoria de desempregados, não se pode negar a importância das várias dimensões que o trabalho ocupa nas nossas vidas. Ele é uma contribuição fundamental na manutenção ou no resgate da saúde mental de cada indivíduo. 0 cuidado como promotor de autonomia é um cuidado permeado por um olhar que considera o sujeito sofredor como cidadão, com uma perspectiva de reinserção psicossocial. Assim:

(...) Eu acho que o princípio fundamental é poder ouvir, poder respeitar e entrar nessa lógica. Porque, [é] o que acontece em respeitar o plano terapêutico. 0 que é o Plano Terapêutico? 0 que eu quero para mim, o que eu quero para a minha vida. Bom eu quero uma casinha, eu quero morar sozinho, eu quero voltar para a minha família. [...] Porque, [é] assim o que a gente tem entranhado em nós?_Nossos valores, os nossos conceitos, e, com isso, muitas vezes, a gente quer colocar neles. (Expira a Respiração).

Uma das alternativas para a reinserção psicossocial do sofredor é a vivência do trabalho. Na Reforma Psiquiátrica Italiana, o sofredor psíquico através da experiência em cooperativas de trabalho protegidas entra em contato com situações de inclusão social e cidadania (Rotelli12:157). Essa experiência na Itália contou com os trabalhadores de saúde mental pagos pela administração pública e utilizou todo e qualquer espaço físico e outras contribuições do poder público para fomentar o que no Brasil denominamos cooperativas de trabalho. 
A rede de saúde vem investindo em novas modalidades, e, em cada uma delas, devem ser definidas as diretrizes que apontem para a autonomia do sofredor, como parâmetro para sua recuperação. É importante destacar que, ao longo desses anos, alguns serviços se consolidaram como referência para as ações de saúde mental. Estes serviços estabelecem estratégias que possibilitam ao trabalhador de saúde mental uma mudança de postura diante do sofredor. Os trabalhadores tornam-se mais flexíveis na realização de ações terapêuticas, e o próprio trabalho vai tecendo-se à medida que ele acontece:

(...) 0 serviço de saúde mental foi se constituindo e construindo os momentos dentro da comunidade. Foi através de uma fala na associação de moradores do bairro que nasceu a equipe de saúde mental e o trabalho na comunidade (Expira a Respiração).

0 ponto de partida para as mudanças de concepções, que não acontecem do dia para noite, são todos: os trabalhadores, usuários e familiares. É preciso uma compreensão diferenciada sobre as novas ações em saúde mental. A nova lógica proposta pela Política de Saúde Mental configura-se a partir de: integração de alguns projetos unindo as ações de saúde e saúde mental; a criação de espaços férteis na conquista da reabilitação em saúde mental; e a qualidade na troca de informações entre os trabalhadores de saúde mental. Estes são pontoschave para o avanço e consolidação desse novo modelo. Uma das formas de produção da autonomia acontece através do reconhecimento dos direitos humanos, por parte da sociedade. Entre eles se destacam: o direito ao trabalho e 0 direito a receber um pagamento justo, por exemplo.

A (re)inserção social do sofredor psíquico, que se produz através de qualquer atividade laboral, implica no desenvolvimento de algumas dimensões, tais como: física, psicológica, social e econômica, fazendo com que esse sofredor se sinta partícipe da comunidade, o que contribui para a melhoria de sua capacidade de responsabilidade, suas relações sociais e compromisso com os outros que desenvolvem uma mesma atividade. A construção da cidadania plena, ponto fundamental da reabilitação psicossocial, depende de variáveis que operam contra ou a favor da contratualidade em casa, no trabalho e na rede social. Tudo o que se posiciona contra essa contratualidade está contra a reabilitação (Saraceno ${ }^{13: 17}$ ).

0 fato de o sofredor tornar-se responsável por seus atos faz parte do processo de reabilitação, o que implicaria numa maior capacidade de discriminar as condições prescritas pela sociedade e assumir 0 compromisso de intervir como ator e autor do processo do trabalho. 0 sofredor, ao se sentir participante de um processo de trabalho, tende a se responsabilizar pelo mesmo. Essa participação proporciona-lhe uma consciência mais ampla de si mesmo e dos meios de produção, o que possibilitará o desenvolvimento da sua liberdade de opção diante não apenas do contexto do trabalho, mas da própria vida. Aliado ao conceito de reconstrução de cidadania aparece o conceito de autonomia, como um operador terapêutico. Para Kinoshita ${ }^{14: 57}$, a autonomia significa a capacidade de um indivíduo gerar normas, ordens para sua vida, conforme as diversas situações que enfrenta. A imagem de dependência e heteronímia adjudicada ao sofredor psíquico pelo imaginário social ocasiona, nesse mesmo sujeito, um estado de exaustão que inviabiliza a priori qualquer possibilidade de alcançar um estado de autonomia. Por outro lado, uma estratégia para promover a mudança desta visão no imaginário social , sem dúvida, seria a ampliação de fatores de nãodependência, para se reconhecer no sofredor um sujeito com direitos expressados, por exemplo na sua participação efetiva na própria elaboração do plano terapêutico, para o qual propõe, concorda e negocia os passos a serem seguidos no tratamento:

\section{(...) A paciente queria manter a medicação dela} amamentando, e ele dizia que não, que ela não poderia manter a medicação, que ele era 0 médico, que sabia o que era melhor para ela. $E$ ela dizia: Mas eu sei o que é melhor para mim. $E$, aí, o que nós dizíamos para ela [era]: "Tu sabes o que é melhor para ti, realmente. Então, a gente vai te ajudar nisso. Assim, tu sabes o que é melhor para ti e tu vais te sentir segura". Aí, fizemos todo um outro viés, um outro caminho, medindo custobenefício para ela e para o bebê para que ela ficasse bem, e hoje ela está bem. [...]. Então, eu acho que no cuidar, tratar, fazer planos terapêuticos, o usuário tem que estar envolvido diretamente, ele é a figura central. (Corpo / Alma).

Respeitar o sofredor, o direito dele de decidir sobre o que é melhor para sua vida, deve ser um dos cuidados ao se formular plano terapêutico. Este plano não pode se transformar numa ação hegemônica. Ao contrário, ele é uma construção entre os dois autores desse processo. Claro que sempre cabe ao trabalhador de saúde mental orientar sobre qual a melhor conduta e/ ou sobre quais serão os riscos inerentes a cada uma das opções apresentadas. Mas, a palavra final deve ser do sofredor, ou, como refere Mariotti15: (...) se a vida é 
um processo de conhecimento, os seres vivos constroem esse conhecimento não a partir de uma atitude passiva, e sim pela interação. Aprendem vivendo e vivem aprendendo (Maturana et al. ${ }^{16: 12}$ ). Assim:

(...) Eu trabalhava numa multinacional, era um executivo que pensava só em ganhar dinheiro e cheguei até a ganhar. Mas, depois que meu filho adoeceu, eu abandonei tudo. Fiz uma piscina no quintal de uma casa que eu morava e fiquei lá muito anos. Vivendo daquilo que eu fazia e dando atenção para o meu filho. Depois, ele foi se tratar no serviço aberto. Ele ainda estava internado, saiu para o serviço aberto. Hoje ele nem freqüenta mais o CAPS, (...) tem uma vida relativamente autônoma. $E$ enfim, nós vivemos juntos (No peito traz).

No trabalho de saúde mental, o sofredor psíquico necessita de uma abordagem que seja atentiva às várias dimensões da vida humana. 0 cotidiano da vida passa a fazer parte do trabalho terapêutico. $A$ atenção em saúde mental é mais que medicar ou fazer psicoterapia. É participar, junto com o outro (sofredor) da relação, na construção de uma vida com inserção social. Concordamos com Maturana et al. ${ }^{16: 14}$, quando referem que os seres vivos são autônomos, isto é, autoprodutores - capazes de produzir seus próprios componentes ao interagir com o meio: vivem no conhecimento e conhecem no viver. Neste sentido:

(...) Eu acho que o conhecimento é muito importante! Não só das tuas leituras, mas também de tua prática, de tua experiência. Uma coisa que é importante é estabelecer com essa pessoa o contrato: o que é que ela deseja, que rumos ela quer tomar, se ela quer se cuidar. Eu acho isso fundamental, o contrato. 0 importante é construir o plano terapêutico junto com ela (Expira a Respiração).

Neste discurso-objeto observa-se que na autonomia existe certo grau de heteronomia. Somente ao considerarmos os seres humanos isoladamente podemos imaginá-los como seres autônomos. É na relação estabelecida entre 0 sofredor e 0 trabalhador de saúde mental que se pode observar, utilizando a metáfora "uma via de mão dupla", que autonomia e heteronomia se alternam no encontro terapêutico. Assim, novamente Maturana et al. ${ }^{16: 14}$ diz que, (...) autonomia e dependência deixam de ser opostos inconciliáveis: uma complementa a outra.

Nessa relação de autonomia versus heteronomia, o contrato de cuidado, ao ser estabelecido com o sujeito sofredor, deve priorizar sua história de vida, a cultura em que está imerso e suas particularidades, bem como suas inter-relações na sociedade. Deve haver o reconhecimento de que cada sujeito tem um conhecimento pessoal sobre seus limites e potencialidades, o que permite construir um plano terapêutico compartilhado, a partir de uma ética humanista. 0 depoimento a seguir exemplifica esta posição:

(...) Eu acho que a formação é prioritária, ela dá a base, (...) mostra o caminho. Mas, se a pessoa não tiver essa sensibilidade, essa coisa humanística, essa relação apaixonada de compaixão é difícil, porque, se não, ele vai bater na barreira das várias linhas terapêuticas, e aí me parece que fica uma coisa pobre (...). Eu acho que quando se cuida, você tem que pensar no sujeito como ser humano. E não como um prontuário, como uma ficha (...) arquivada, um diagnóstico (No Peito Traz).

As diferentes falas apresentadas apontam para uma mesma questão prioritária, ou seja, o vínculo terapêutico, entendido como a humanização da relação entre o trabalhador de saúde mental e o sujeito sofredor. É nessa relação humanizada, dialógica, que se estabelece a possibilidade de reconhecimento do outro (sofredor) como ser autônomo, o que possibilita uma abordagem do indivíduo como um todo, vendo seus aspectos sócio-econômico-culturais, no contexto em que ele está inserido. A humanização na relação terapêutica, assim como é assinalada nos diferentes discursos, origina-se na sensibilidade do cuidador. Esta sensibilidade vem permitir um fluxo de paixão e compaixão pelo sujeito sofredor e reconhece que a loucura é acompanhada por um grau de sofrimento mental.

0 horizonte dessas transformações passa pelo cumprimento da Lei $10.216^{17}$, mas, também, pela conscientização de que todas as pessoas são cidadãs, têm direito à saúde, morar e trabalhar, não podendo ser excluídas do social e estigmatizadas pelo fato de serem portadoras de sofrimento psíquico. Sobre esta questão, Lancetti ${ }^{18: 140}$ questiona: tratar-se-ia de substituir a utopia despótica, que consiste em transformar a loucura em doença mental, numa doce captura do diferente, com o argumento democrático de que todos somos cidadãos?

Nessa mesma direção encontra-se 0 posicionamento teórico de Pelbart ${ }^{19: 136:}$ : Trata-se enfim, de um pensamento que não transforma a Força em acúmulo, mas em Diferença e Intensidade. Isso tudo implica naturalmente, em inventar uma nova relação entre corpo e linguagem, entre subjetividade e a exterioridade, entre os devires e o social, entre 0 
humano e o inumano, entre a percepção e o invisível, entre o desejo e o pensar. Corroborando esta idéia, Kinoshita ${ }^{20}$ aponta para a necessidade de transformar os modos de "tratar" o sujeito sofredor em possibilidade de transformação do sofrimento.

Neste sentido, o discurso a seguir ilustra a possibilidade de substituir uma postura derivada do modelo tradicional de assistência pela Diferença e Intensidade, através da busca de crítica sobre a ação terapêutica:

... Por um tempo, eu tive a psicóloga, como um trabalho individual. Depois eu passei para o trabalho de grupo, que era onde o pessoal acabava falando mais, conversando, e depois a pessoa estava bem. Mesmo assim, acabava permanecendo no grupo para incentivar o pessoal que estava entrando no grupo. Só o fato de tu estares ali do lado [no grupo] e ele estar vendo que tu estas ali e que tu estás solidário com ele, eu acho que já ajuda, e muito, para que essa pessoa saia desse momento de crise que ela está vivendo (Garganta Grita).

A estratégia apontada neste discurso-objeto traduz o sentimento de solidariedade entre as pessoas. 0 grupo terapêutico ou de trabalho, como é referido na fala, traz uma outra forma de organização. Mesmo aquele sujeito sofredor que já está "apto" a deixar o grupo, permanece solidário com aquele que ingressa, por mais algum tempo. Portanto, ele apresenta maior dificuldade para visualizar a possibilidade de recuperação e inserção social:

... Você tem que abrir espaço numa sociedade excludente, para que aquelas pessoas que são mais frágeis encontrem um lugar para e como viver. Então, na verdade, a própria organização de associações de pacientes e associações de familiares são investimentos no campo de produção de autonomia e da cidadania possível. Essas expressões (...), o campo da saúde mental utiliza muito. A cidadania construída no dia-adia é a autonomia possível de todos esses pacientes. Essa é a idéia que eu tenho dessa clínica antimanicomial (Espinha Dorsal).

A experiência histórica relatada neste discursoobjeto sugere que a igualdade perante a lei foi uma conquista essencial do grupo de sujeitos sofredores para a consolidação do serviço alternativo de saúde mental. A garantia de um serviço de saúde mental só foi conquistada pela participação ativa de usuários, familiares e trabalhadores de saúde mental perante 0 poder público municipal. 0 princípio da igualdade perante a lei inaugura e define um novo ciclo histórico.
Este aspecto tem reflexos ainda na própria visão e análise do processo saúde/doença mental do sofredor psíquico: A situação psicoterápica transcende a dicotomia normal/patológico sendo construída pari passu na relação. Será neste "encontro" com o sujeito sofredor como um "ser", e não como um "corpo doente", que teremos o esboço do diagnóstico, precário por natureza, mas evidenciando o que é mais refinado em seu psiquismo.

Estes pontos são lembrados por Castel ${ }^{21: 295}$, em sua referência ao personagem do "alienista", como um especialista do perigo. Historicamente como um encarregado de um perigo para o corpo social: (...) ele se postou como o sentinela de uma ordem que é a da sociedade em seu conjunto. Assim, os discursosobjeto apresentados a seguir exemplificam como vem mudando o "sentinela" da ordem social:

... O diferencial do cuidado, para não ser simplesmente um cuidado assistencial ou um cuidado geral, é que [ele] deve permitir ao outro se cuidar e fazer parte de uma cidadania. A inclusão do sofredor, para isso, é cada vez mais importante (...). Então, essa nova forma de cuidar que nos foi proposta e que a gente luta por mantê-la é a de colocar a disposição de todos os usuários o direito às políticas sociais, de conscientizá-los para o direito à moradia, direito ao trabalho, direito ao benefício da previdência, de resgate de cidadania dessas pessoas, que possam ser tiradas da pobreza que Ihe é imposta, pelo menos para a grande maioria dos doentes mentais, no Brasil (Potência).

... Eu sou profissional e tu és só um paciente ou alguém que está precisando dos meus cuidados. Não, eu sou alguém como tu, que neste momento estou em melhores condições psicológicas e por isso (...) posso te ajudar agora. Mas daqui a algum tempo, quem garante que tu não estarás em melhores condições e eu vou precisar do teu sorriso, da tua mão? (Estatura Mediana).

A função do trabalhador de saúde mental nessa outra abordagem de cuidado implica, sim, na conscientização do sujeito sofredor para a participação e o conhecimento dos seus direitos relativos às políticas sociais, como uma forma de emancipá-lo. Tais idéias foram debatidas no Fórum Nacional ${ }^{22}$ realizado em Brasília, em 2000, e promovido pelo Conselho Federal de Psicologia. Seu tema foi "Como anda a Reforma Psiquiátrica Brasileira? Avaliação, Perspectivas e Realidades". Entre as várias recomendações do Fórum, duas delas diziam respeito ao controle social. A 
multiplicidade de trocas afetivas/sociais, ao serem favorecidas nos serviços alternativos, permite 0 reconhecimento pessoal dos limites e potencialidades de cada sujeito sofredor e atua diretamente na promoção de sua auto-estima; estimula sua sensibilidade para com a natureza e promove a solidariedade nas relações sociais. Então, exemplificando essa multiplicidade e possibilidades de resgate pelo sujeito sofredor, o discurso-objeto apresentado a seguir destaca que:

... Os serviços de atenção à saúde mental constituem uma expressão do movimento social que recusa toda e qualquer forma de violência e exclusão para com o sofredor psíquico. Apesar disso, já foi possível observar, nos novos serviços, que o diagnóstico pode ser médico, mas o tratamento não o é (Sobrancelhas).

Os aspectos apresentados neste discurso-objeto levam a considerar a fala de Bertolote $e^{23: 156}$ sobre sua prática atual à frente do trabalho de Reabilitação Psicossocial:

Nós entendemos que Reabilitação Psicossocial é fundamentalmente um processo de remoção de barreiras (...), que impedem a plena integração de um indivíduo na sua comunidade e de barreiras que impedem o pleno exercício de seus direitos, da sua cidadania.

A rede social proposta nos discursos sobre 0 modelo de tratamento passa pela eliminação de barreiras; pelo favorecimento à manutenção dos vínculos do sujeito sofredor com a família, o trabalho e a própria sociedade; e pelo fortalecimento de laços de solidariedade. Portanto, os serviços de atenção à saúde mental devem estar atentos às condições de favorecimento dos vínculos familiares, como um princípio da qualidade da atenção prestada.

\section{DIREITOS HUMANOS COMO POSSIBILIDADE DE RELAÇÕES COM AS DIFERENÇAS}

0 desenvolvimento de uma cultura de promoção dos direitos humanos nos serviços de atenção à saúde mental inclui um patamar ético, que deve mediar todas as relações que se estabelecem no interior do mesmo. É preciso que o trabalhador de saúde mental fomente, permanentemente, cidadanias ativas e processuais articuladas à luta pelos direitos humanos, em todas as instâncias institucionais reguladoras da atenção em saúde mental, como forma de reduzir as desigualdades, a opressão e 0 assistencialismo e garantir os direitos sociais do sujeito sofredor. 0 direito à educação, à saúde, ao trabalho e ao lazer é o requisito essencial ao pleno exercício dos direitos civis e políticos do cidadão. Neste sentido, Foucault 24:297 posiciona-se para não se deixar cair nas armadilhas do próprio Estado, no que diz respeito ao poder como inibidor de plenos direitos civis e políticos do cidadão:

Se é verdade que a lei universal é igualitária com que se sonhava no século XVIII serviu de instrumento a uma sociedade de desigualdade e exploração, nós caminhamos, com largas passadas, para uma sociedade extrajurídica na qual a lei terá por papel autorizar intervenções coercitivas e reguladoras sobre os indivíduos.

0 Movimento da Reforma Psiquiátrica e o Movimento Nacional da Luta Antimanicomial produziram importantes avanços ao denunciarem as práticas desumanas e a falta de terapêutica dos hospitais psiquiátricos. Esses dois movimentos mobilizam-se na denúncia permanente à limitação dos direitos de cidadania do sofredor psíquico, bem como pelo respeito à sua autonomia. Assim, 0 reflexo desses movimentos pode ser exemplificado a seguir, no discurso-objeto sobre o envolvimento de pessoas que estão no entorno do sofredor psíquico:

... Até porque alguns profissionais entendem que o seu jeito de viver a vida deve ser o melhor para a outra pessoa. Acredito que o sofredor possa, sim, se expressar da forma que entende que deva se expressar e ajudar as outras pessoas também de seu entorno. Entendo que não só se deve cuidar de quem está em sofrimento, mas também temos que cuidar daquele que está no entorno do sofredor (Espinha Dorsal).

A abordagem de cuidado proposta no discursoobjeto constitui-se hoje num modelo de atenção que contempla a família. 0 modelo que contemplar a saúde em suas múltiplas dimensões é o modelo adotado no Programa de Saúde da Família (PSF). A ampliação do objeto de atenção, do individual para o coletivo, retrata uma das características que a Política Nacional de Saúde Mental busca consolidar. Este estilo de abordagem em saúde mental combina diversidade, ousadia, velocidade na ação, criatividade e eficácia, na medida em que presta atenção ao grupo familiar ampliando o foco para além do indivíduo que apresenta sofrimento. Em outras palavras, essa idéia é apresentada por Lancetti ${ }^{18: 23}$, quando diz que quando há um louco, um drogado ou um violento numa família tende-se a observar somente esse membro do grupo. Nosso paciente é a familia toda. É fundamental olhar para todos e para a maneira como se tratam entre si.

A idéia da invenção de outros modos de tratar a loucura deve fazer parte da abordagem de cuidado. 
Buscar novas formas de atenção que minimizem o preconceito, a exclusão do sujeito sofredor do seu meio social. Essa nova abordagem deve observá-lo primeiro como um cidadão e, depois, como alguém que sofre e que necessita do apoio psicossocial. A realidade nos posiciona diante de novos desafios. É preciso criar ou promover a ampliação de espaços férteis de cidadania na atenção em reabilitação. Essa proposta une-se a outra que está alicerçada no conceito de saúde mental, que congrega as noções de condição desejada de bemestar dos indivíduos e das ações necessárias que possam determinar essa condição (Saraceno ${ }^{13: 152}$ ).

Assim, a saúde mental é, antes de tudo, um conceito complexo, pois é substancialmente construtor de dimensões psicológicas e sociais da saúde que determinam o processo saúde/doença. Tendo em vista esses dois aspectos, vale destacar o discurso-objeto a seguir:

... Porque a questão da convivência nos aproxima muito, nos mostra muito da pessoa. $E$ a outra coisa é o olhar, porque que tu podes conviver o dia inteiro, olhar a pessoa e não olhar para ela. As duas coisas com certeza. Porque assim é o que acontece. Eles geralmente quando não estão bem já nos mostram, eles começam a nos dizer. E mesmo antes de nos dizer, alguém já disse assim: Fulano, hoje, não está bem, tem alguma coisa incomodando ele. E, aí tu vais lá, dá uma boa tarde, e de fato tem alguma coisa que está incomodando e ele não está bem. Então, é produto da convivência, mas também é produto desse olhar. Tu estás olhando para o outro. Esse é o nosso trabalho (Corpo/Alma).

Neste discurso-objeto existe uma preocupação com - "estar atento", para observar, compreender e conhecer as necessidades do sujeito sofredor, no momento em que elas surgem, bem como valorizar as suas realizações e saberes, aceitando-o como realmente é e como se apresenta no mundo. Não se deve esquecer, também, que muitas dessas pessoas que são atendidas estiveram internadas, em algum período de suas vidas, em hospitais psiquiátricos. Portanto, esse estigma faz com que exista um certo grau de desconfiança por parte do sujeito sofredor, a respeito do trabalhador de saúde mental. Para que os efeitos dessa desconfiança possam ser minimizados, precisamos ser cuidadosos no cumprimento do contrato terapêutico, o que irá favorecer a continuidade do atendimento.

Os discursos apontam para um modelo de atenção coletiva em saúde mental que favorece 0 reconhecimento do sofredor psíquico como sujeito de direitos e deveres. A contextualização desse sofredor, como alguém que pertence a um espaço/tempo determinado de um grupo social favorece uma maior compreensão do seu sofrimento e permite uma ação terapêutica mais condizente com a realidade vivida:

... Se eu tiver um CAPS e (...) não tiver o controle social junto vai acontecer aquilo que eu digo: que manicômio não é uma estrutura da engenharia como construir um prédio, que não é um substantivo, mas é um verbo conjugado no presente do indicativo. 0 cara conjuga assim: eu "manicomeio", tu "manicomeia", ele "manicomeia" (...). Só existe manicômio, quando existe um verbo, quando existe ação. $E$ a ação é feita por gente que transforma qualquer lugar em manicômio (Potência).

0 controle social como estratégia de garantia dos direitos do sofredor psíquico apontado nesse discursoobjeto é, não somente, uma intervenção necessária para garantir o cumprimento da legislação em saúde mental, mas também uma forma de assegurar o ideário ético-político que norteia a abordagem antimanicomial. Existe a necessidade de se estabelecerem vínculos, laços de compromisso e de co-responsabilidade entre os trabalhadores de saúde mental, sofredores psíquicos, seus familiares e a população em geral:

Aos desiguais devemos tratá-los de forma desigual. Igualdade é para quem é igual. Kant disse isso na sua concepção de Estado. É para quem é igual. Saiu uma matéria de um cientista analisando a obra de Kant e ele trouxe uma metáfora: Para Kant, o Estado é como se fosse um guarda de trânsito, o papel do Estado seria cuidar para que os carros não se "pechassem", que não avançassem o sinal. A questão que se coloca é: todos têm carro? (risos). Então, eu acho que essa visão conservadora, elitista, liberal, para mim, é que está no cerne do problema que vai atingir o cuidado. Porque, se não, tu continuas reproduzindo a lógica liberal: "- esse cara não é igual a mim; o que ele tem a ver comigo? (Almas da Mãe).

Uma abordagem antimanicomial não pode partir da premissa da igualdade entre as pessoas, da homogeneidade entre os seres humanos, bem como da visão de que cada sujeito sofredor é equivalente ao outro e sem diferenciação entre si. Essa outra concepção de cuidado em saúde mental considera as desigualdades entre os seres humanos; as multiplicidades culturais; as heterogeneidades e as singularidades pessoais. 
Para tanto, é preciso construir um novo pensar/fazer nessa prática, que requer o desenvolvimento de habilidades e mudanças nas atitudes dos trabalhadores de saúde mental. A interação do trabalhador de saúde mental seja com o sofredor, seja com os familiares, seja com a população em geral deve pautar-se pelo respeito às diferenças e à diversidade dos sofredores, caracterizando o que podemos chamar de sensibilidade terapêutica. Neste sentido, o sucesso pode ser alcançado:

... Quando tu vês que, nas novas experiências em saúde mental, as pessoas conseguem se relacionar, a partir de uma outra proposta, de um outro jeito de tratar (Angina do Peito).

Cabe destacar a ênfase que é dada no reconhecimento das diferenças entre as pessoas. A diversidade, quando reconhecida, faz com que os trabalhadores de saúde mental transformem a filosofia de "tratar" a todos da mesma maneira. Reconhecer as diferenças entre os sujeitos sofredores e responder a elas com o objetivo de dar suporte e agregar novas perspectivas de resolução dos conflitos é o desafio que se estabelece na saúde mental nesse milênio que se inicia para trabalhadores de saúde mental. Assim:

... A gente tem que assumir vários papéis, não ser só um técnico. E hoje, depois de várias andanças, eu já vi as conseqüências, por exemplo, de alguém que coordena a saúde mental somente de forma técnica ou somente de forma política. Eu acho que se deve ter várias visões desse trabalho, para poder realmente fazer com que ele ande e fazer com que ele possa se integrar e estar dentro do todo que envolve tanto o poder público quanto as comunidades. Se inserir realmente nas vidas das pessoas (Expira a Respiração).

Na verdade, os trabalhadores de saúde mental estão fortalecendo os usuários dos serviços, ao posicioná-los no comando de certas atividades grupais desenvolvidas para a reabilitação psicossocial. Para isso, estão aprendendo a delegar o controle e os sujeitos sofredores, a ter a oportunidade de demonstrar responsabilidade sobre um trabalho e tomar decisões mais apropriadas:

... Então, naquele momento em que ele está necessitando da tua presença, da tua palavra, tu tens que tratar ele conforme tu gostaria de ser tratado. Então, com certeza, tu não irias querer ser tratado de uma maneira ríspida. Então, eu acho que a primeira coisa é isso, os cuidados, quer dizer, a pessoa ter todo um preparo para lidar com determinadas situações porque nem todo sofredor psíquico é tranqüilo, tem um pessoal que se agita demais, que fica agressiva ... então, tu tens que ter um preparo de como lidar com esse tipo de pessoa (Garganta Grita).

Os sofredores psíquicos de determinado serviço podem constituir-se em mola propulsora da inovação e mudança na atenção em saúde mental, ou podem ser uma barreira poderosa contra ela. 0 desafio é 0 estímulo para criatividade e tolerância à mudança. Os trabalhadores de saúde mental precisam aprender a lidar com a temporalidade, bem como a conviver com a flexibilidade, a espontaneidade e a imprevisibilidade próprias do pensar/fazer em saúde mental. As ações empreendidas pelos trabalhadores de saúde mental ilustram suas habilidades, sua filosofia de vida ou visão de mundo e suas vivências. Para atender a uma outra compreensão da loucura, responder às necessidades dos sofredores e cumprir com a legislação em saúde mental é preciso reconhecer as conexões e interfaces existentes no processo de cuidado destacando-se, entre elas, a preservação das diferenças técnicas entre os profissionais e a flexibilização das fronteiras entre as diversas áreas profissionais; a minimização da hierarquização das diferentes áreas de trabalho; e a promoção da interação como prática comunicativa, por meio das quais todos participem do objetivo comum.

Nos discursos-objeto apresentados surge a necessidade dos sofredores e familiares em participar do cuidado, ou seja, a necessidade de inclusão do sofredor e da família nas discussões e formulações da assistência. Aliadas a esta idéia, as ações dos trabalhadores de saúde mental devem romper com a lógica criada a partir do estabelecimento da razão como princípio regulador entre o normal e o anormal e gerar uma outra lógica mais solidária, tolerante e promotora do desenvolvimento pessoal e social das pessoas com sofrimento psíquico. Um ponto a ser destacado diz respeito ao fato de que o trabalhador de saúde mental não tem uma fórmula pronta e acabada, uma "receita de bolo", para dar respostas às necessidades do sujeito sofredor. Essas respostas precisam ser construídas no cotidiano do trabalho, na interação entre os trabalhadores, usuários dos serviços, familiares e comunidade em geral. Arejano ${ }^{25: 218}$ refere que a atenção à saúde mental é uma construção diária como o café, e é preciso que estejamos atentos ao contexto e ao complexo da situação. Assim, o trabalho terapêutico é uma construção diária, mas também é uma construção compartilhada na qual contribuem os trabalhadores e sofredores psíquicos e os familiares. 


\section{CONSIDERAÇÕES FINAIS}

Ao encaminhar a finalização deste estudo centrado na reflexão de uma abordagem antimanicomial aderente à nova compreensão do sofredor psíquico, como sujeito complexo e subjetivo em si próprio, pretendeu-se estar em consonância com as exigências deste novo tempo e em sinergia com o compromisso ético da equipe de saúde, dentro da utopia e da luta por "uma sociedade sem exclusão". A vinculação deste trabalho com a realidade é a estratégia necessária para a nova compreensão e reordenação do cuidado em saúde mental, que se pretende.

$\mathrm{Na}$ discursiva sobre a verdade foucaultiana, Rabinow e Dreyfus ${ }^{9}$ salientam que o verdadeiro dito a tempo e a quem de direito por aquele que é o seu detentor, cura. 0 campo das políticas públicas em saúde tem se destacado pela capacidade de propor mudanças. Neste sentido, ele pode ser considerado como o campo que mais avançou em termos de reformas administrativas, políticas e organizativas. Muitos são os fatores que têm influenciado sobre as mudanças no setor saúde, de forma positiva ou negativa.

Em contrapartida, a Reforma Psiquiátrica demanda tempos distintos, enquanto estratégia de reorientação da atenção voltada para um paradigma sanitário de produção social da saúde, uma vez que as mudanças decorrentes são da ordem político-ideológica, e não somente da ordem técnico-científica. De outro lado, uma integração da teoria às práticas e uma compreensão do sentido profissional desses fazeres diante das demandas tornam-se indispensáveis, pois a história da Reforma está sendo escrita.

Trabalhadores de saúde mental, usuários, familiares, homens e mulheres estão conscientemente em ação através da força de seu trabalho e do engenho de suas lutas, para fazer da utopia por uma sociedade sem exclusão uma realização no presente, e do lema por uma sociedade sem manicômios um compromisso

\section{Referências}

1 Foucault M. Vigiar e punir. 4ªed. Petrópolis(RJ): Vozes; 1986.

2 Ey H. Tratado de psiquiatria. $8^{\text {a }}$ ed. Barcelona(ES): Toray-Masson; 1978. p. 2000.

3 Morin EA. Cabeça bem-feita: repensar a reforma, reformar 0 pensamento, Rio de Janeiro(RJ): Bertrand Brasil; 2000. p. 51.

4 Minayo MCS. 0 desafio do conhecimento: pesquisa qualitativa em saúde. $7^{\text {a }}$ ed. São Paulo(SP): Hucitec; 2000.

5 Trentini M, Paim L. Pesquisa em enfermagem uma modalidade convergente assistencial, Florianópolis(SC): Ed. da UFSC; 1999. com o futuro. Assim, é necessário procurar alternativas para efetivar práticas que respondam à nova realidade e aos problemas de um modelo de atenção à saúde mental baseado na lógica da igualdade e dos direitos humanos. Esta consciência já faz parte do pensar e do fazer em Saúde Mental, ou seja, ao se fazer a pergunta: de que modo uma abordagem antimanicomial pode favorecer a compreensão do sofredor psíquico, em seu contexto, como sujeito complexo e subjetivo? Introduzir formas de ações 'diferentes' no campo da Saúde Mental não significa, simplesmente, oficializar 'normas de boas intenções'. Também, um marco norteador estabelecido de cima para baixo, e que será aceito ou deverá ser aceito mais como "ato de fé" do que como verdadeira transformação no interior das diferentes práticas profissionais que compõem o cenário da Saúde Mental, não é por si só promotor de uma nova forma de encarar e compreender a loucura.

A atenção em Saúde Mental, herdeira das políticas disciplinares do conhecimento "psi" deve manter um diálogo permanente para resolver as contradições internas a esse respeito, tanto de seus atores quanto da ideologia que sustenta as suas práticas. Portanto, fazer uma história do presente sobre o cuidado em Saúde Mental significa reconhecer as continuidades e rupturas no dispositivo "saúde mental".

Mudanças de concepções não acontecem do dia para noite e, o ponto de partida somos todos nós trabalhadores, usuários e familiares. É preciso uma compreensão diferenciada sobre as novas ações em saúde mental. A nova lógica proposta pela Política de Saúde Mental; a integração de alguns projetos unindo as ações de saúde e saúde mental; a criação de espaços férteis na conquista da reabilitação em saúde mental e a qualidade na troca de informações entre os trabalhadores de saúde mental são pontos-chave para o avanço e consolidação desse novo modelo. É preciso que se construam espaços potenciais de intercâmbio e renovação no dia-a-dia dos serviços e nas instituições formadoras.

6 Richardson RJ. Pesquisa social: métodos e técnicas. $3^{\mathrm{a}}$ ed. São Paulo (SP): Atlas; 1999.

7 Lisboa MTL. Ética na pesquisa de enfermagem. Esc Ann Nery Rev Enferm 2006 abr; 10(1): 09-14.

8 Rosario AB. Da biblioteca digital: bibliografia internacional anotada. [on-line] [citado 27 set 2002] Disponível em: http:// www15.vianetworks.com.br/casadasrosas/trans/bispo/bispovd.htpm 9 Rabinow P, Dreyfus H. Michel Foucault: uma trajetória filosófica para além do estruturalismo e da hermenêutica. Rio de Janeiro(RJ): Forense Universitária; 1995.

10 Ortega F. Amizade e estética da existência em Foucault. Rio de Janeiro(RJ): Graal; 1999. 
11 Lancetti A et al. Saúde e loucura, 2ª São Paulo(SP): Hucitec; 1990.

12 Rotelli F. Superando o manicômio: o circuito psiquiátrico de Trieste. In: Amarante P. Psiquiatria social e reforma psiquiátrica. Rio de Janeiro(RJ): Ed da FIOCRUZ; 1994.

13 Saraceno B. Reabilitação psicossocial: uma estratégia para a passagem do milênio. In: Pitta A, organizador. Reabilitação psicossocial no Brasil. São Paulo(RJ): Hucitec; 1996.

14 Kinoshita RT. Contratualidade e reabilitação psicossocial. In: Pitta A, organizador. Reabilitação psicossocial no Brasil. São Paulo(SP): Hucitec; 1996.

15 Mariotti H. Prefácio. In: Maturana HR,Varela FJ. A árvore do conhecimento: as bases biológicas da compreensão humana. $3^{\mathrm{a}} \mathrm{ed}$. São Paulo(SP): Palas Athena; 2003.

16 Maturana HR, Varela FJ. Aárvore do conhecimento: as bases biológicas

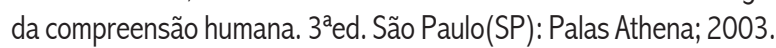

17. Lei $N^{0} 10.216$, de 06 de abril de 2001. Dispõe sobre a proteção e os direitos das pessoas portadoras de transtornos mentais e redireciona o modelo assistencial em saúde mental. [on-line] [acesso 10 abr 2006]. Disponível em: http://www.planalto.gov.br/ccivil/leis/ LEIS_2001/L10216.htm

18 Lancetti A. A modo de Posfácio. In: Marsiglia RDA; Dallari DA; Costa JF; Moura Neto FDN; Kinoshita RT; Lancetti A. Saúde mental e cidadania. $2^{a}$ ed. São Paulo(SP): Mandacaru; 1990.

19 Pelbart PP. Manicômio mental: a outra face da clausura In: Lancetti A, organizador. Saúde e loucura. $3^{\text {a }}$ ed. São Paulo(SP): Hucitec; 1992.

20 Kinoshita RT. Em busca da cidadania: desinstitucionalização de um hospital psiquiátrico. In: Campos BCF, Maierovitch C, organizadores. Contra a maré à Beira-Mar: a experiência do SUS em Santos. São Paulo(SP): Hucitec; 1996.

21 Castel R. La contradicción psiquiátrica. In: Basaglia F, organizador. Los crimenes de La Paz: investigación sobre los intelectuales y los técnicos como servidores de la opresión. México: Siglo Vienteuno; 1977.

22 Rolim MI. $1{ }^{\text {a }}$ Caravana Nacional de Direitos Humanos: uma amostra da realidade manicomial brasileira. Brasília(DF): Câmara dos Deputados, Coordenação de Publicações; 2000 [on-line] [acesso 22 set 2005]. Disponível em: http://www2.camara.gov.br/comissoes/ c d h m/relatorios/Apresenta.htm I/ ?searchterm=1\%20caravana\%20nacional\%20de\%20direitos\%20humanos.

23 Bertolote JM. Em busca de uma identidade para a reabilitação psicossocial. In: Pitta A, organizador. Reabilitação psicossocial no Brasil. São Paulo(SP): Hucitec; 1996.

24 Foucault M. Ditos e escritos, problematização do sujeito: psicologia, psiquiatria e psicoanálise. Rio de Janeiro(RJ): Forense Universitária; 1999.

25 Arejano CB. Reforma psiquiátrica: uma analítica das relações de poder nos serviços de atenção à saúde mental [tese de doutorado] . Florianópolis(SC): PEN/ UFSC; 2002.

\section{Notas}

a Este texto está baseado em Prandoni RFS. Loucura e complexidade na clínica do quotidiano [tese de doutorado]. Florianópolis: Departamento de Enfermagem - Programa de Pós-graduação em Enfermagem / UFSC; 2005, que infelizmente não pode estar entre nós para partilhar de sua luta por um cuidado psiquiátrico livre de preconceitos, de "exame", com respeito à subjetividade dos sujeitos. Raul sempre acreditou na necessidade de repensar a prática e que os estudos teóricos pudessem reflitir sobre as relações entre sociedade e saúde mental. Este texto é um presente e uma homenagem póstuma para você Raul, que em algum lugar com certeza está olhando para nós.

${ }^{\mathrm{b}}$ Adotamos nomes fictícios para os entrevistados oriundos da obra de Arthur Bispo do Rosário intitulada Bordados de uma Existênciå. Os nomes fictícios foram: Almas da Mãe; Corpo/Alma; Garganta Grita; Sobrancelhas; A vista/os Olhos; Expira a Respiração; Hematomas; Espinha Dorsal; No Peito Traz; Potência; Estatura Mediana; Angina do Peito e Clavicular.

\section{Sobre os Autores}

Raul Fernando Sotelo Prandoni (In Memoriam).

Psicólogo. Doutor em Enfermagem pelo Programa de Pós-graduação em Enfermagem da Universidade Federal de Santa Catarina (UFSC).

\section{Maria Itayra Coelho de Souza Padilha}

Professora Associada e Vice-Líder do Grupo de Estudos de História do Conhecimento de Enfermagem (GEHCE), do Departamento de Enfermagem da UFSC. Doutora em Enfermagem pela Escola de Enfermagem Anna Nery / UFRJ. Pesquisadora do CNPq. E-mail: padilha@nfr.ufsc.br. 